\title{
Effect of Bed Roughness on Submerged Hydraulic Jumps
}

\section{Y. Dilrooban, K. Imasalan, K. Sujana and K.P.P. Pathirana}

\begin{abstract}
Free and submerged hydraulic jumps are important phenomena in open channel flow. The basic characteristics of these jumps formed on smooth, horizontal channel beds were covered well in literature both experimentally and theoretically. However, not many studies are reported on submerged hydraulic jumps generated on rough beds. This study mainly aims to investigate the characteristics of submerged hydraulic jumps over rough, horizontal beds. But, as the submerged hydraulic jumps are created from free jumps, analyses of free jumps are also required to proceed with the present study. So, altogether 110 experimental runs were carried out under both smooth and rough bed conditions. All the experiments were carried out in a rectangular flume and for the rough bed condition. Bed of the flume was roughened by placing rectangular wooden strips at four different spacing. The hydraulic parameters such as initial water depths, subcritical sequent depth, tail water depth, back-up depth and flow rates were measured for different roughness. Using these available data, required data analyses were carried out and several relationships were developed in order to express the submerged hydraulic jump characteristics. Here, free and submerged hydraulic jumps were considered separately.
\end{abstract}

Keywords: Tail water depth, Submergence factor, Sequent Depth Ratio, Backup depth ratio, Roughness Density.

\section{Introduction}

Hydraulic jump is an important phenomena in open channel flows which is created by transferring a supercritical flow into a subcritical flow. There are different types of hydraulic jumps depending upon the relative values of subcritical sequent depth and tail water depth. The free jump is converted into a submerged jump, on which our study is mainly focused, when tail water depth becomes larger than the subcritical sequent depth. Hydraulic jumps have been attracted to many researchers for a long period of time because of its importance in designing hydraulic structures and other special applications such as mixing of chemicals, aeration of water, de-chlorination etc. Among all these applications, energy dissipation is considered to be one of the most important applications for civil engineers. Various types of studies have been reported in literature for identification of the characteristics of submerged hydraulic jumps on smooth horizontal beds. Among them, Rajaratnam (1967) was one of the leading researchers who carried out detailed studies to find out a relationship between energy dissipation and submergence factor. Subhasish et. al., (2003) has conducted extensive research work on the characteristics of turbulent flow in submerged jumps on rough beds. From the vector plots of the flow field, it was found out that the rate of decay of jet velocity in a submerged jump increases with increase in bed roughness. As this study was conducted only for uniform sand grains and horizontal bed channels. Furthermore, Habibzadeh et. al., (2011) carried out a preliminary study of the flow properties of submerged jumps with baffle blocks. However, the research studies carried out on submerged hydraulic jumps on rough beds are very limited and most of the studies reported so far do not produce any conclusive results. Therefore, further investigations have to be carried out to get a clear understanding of the characteristics of submerged hydraulic jumps on rough beds.

\section{Methodology}

\subsection{Experimental Set-up}

The experiments were carried out in the Fluid Laboratory in Faculty of Engineering, University of Peradeniya. The flume used for the experiments is of $12 \mathrm{~m}$ long, $0.3 \mathrm{~m}$ wide and a $0.3 \mathrm{~m}$ high (see Figure 1).

Eng. Y. Dilrooban, Eng. K. Imasalan, Eng. K. Sujana.

B.Sc Eng. (Hons) (Peradeniya), Faculty of Engineering,

University of Peradeniya, Sri Lanka.

Eng.(Prof.) K.P.P. Pathirana, B.Sc. Eng. (Hons.)(Peradeniya), M.Eng., Ph.D. (KULeuven), C.Eng., FIE(Sri Lanka), MICE(London). Int.PE(SL), Professor of Civil Engineering, Department of Civil Engineering, University of Peradeniya, Sri Lanka. 


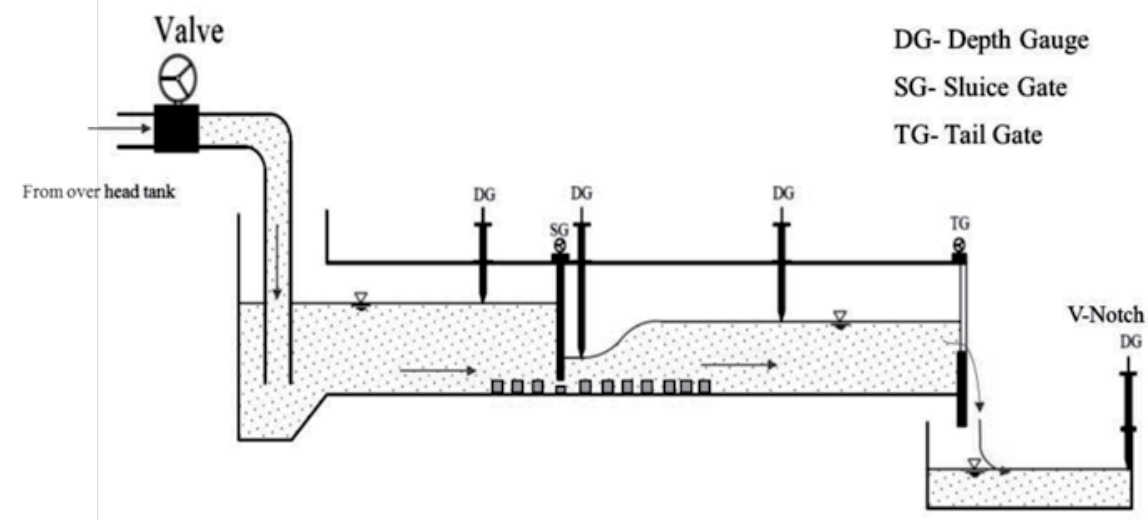

Figure 1 - Schematic diagram of the experimental set-up

Here, an overhead tank with a constant water level supplied the flow to the flume at a constant rate which could be controlled by a gate valve as shown in Figure 1. A V-notch attached at the downstream tank was used to measure the flow rate.

\subsection{Preparation of roughness bed}

The channel bed was roughened using five different types of artificial roughness elements (wooden strips) shown in Figure 2. The cross sections of the elements used in the experiments were $0.8 \times 0.8 \mathrm{~cm}^{2}, 1.2 \times 1.2 \mathrm{~cm}^{2}$, $1.5 \times 1.5 \mathrm{~cm}^{2}, 2.0 \times 2.0 \mathrm{~cm}^{2}$ and $2.5 \times 2.5 \mathrm{~cm}^{2}$. The length of the roughened bed was limited to $2.5 \mathrm{~m}$. The wooden strips were kept to the full width of the flume as shown in Figure 3.

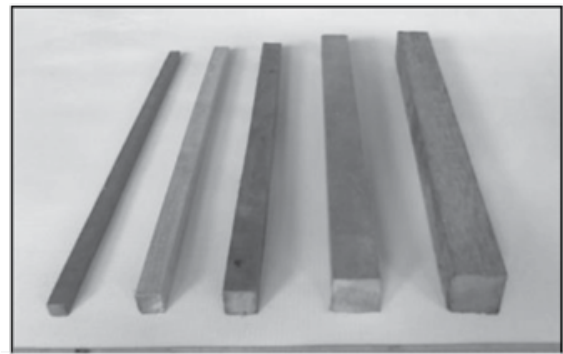

Figure 2 - Roughness elements

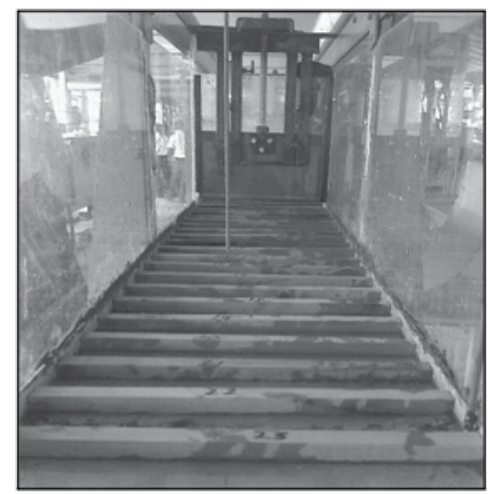

Figure 3 - Roughened bed arrangements
In addition, the spacing between elements $(D)$ was also varied during experiments and the spacing used was $3.0 \mathrm{~cm}, 4.0 \mathrm{~cm}, 5.0 \mathrm{~cm}$, and $6.0 \mathrm{~cm}$.

\subsection{Experimental Procedure}

Initially, several experiments were carried out for submerged hydraulic jumps on smooth horizontal bed. For a particular flow rate, a submerged hydraulic jump was formed by using a sluice gate located at the head of the channels and tail gate at the end of the channel. The flow rate, upstream water depth, downstream water depth and jump length were measured. The flow rate was measured using a $\mathrm{V}$-notch attached to the downstream tank as shown in Figure 1. This procedure was repeated for several discharges in the channel.

Next, several experiments were carried out for submerged hydraulic jumps formed on rough, horizontal channel beds. In this case, roughness elements were firmly fixed on the bed. For each element size, a series of experiments was performed for submerged hydraulic jump by varying the flow rate and spacing between the elements. Similar measurements were taken as in the case of submerged hydraulic jumps formed on the smooth channel bed. This procedure was repeated for the other types of roughness elements. It was always verified that the flow was steady while recording the observations.

\section{Results and Discussion}

\subsection{Comparison of experimental results with the available theories}

As a first step, the experimental data were compared with the available theories on submerged hydraulic jumps. The equation derived by Rao (1963) in Open Channel 
Hydraulics (Chow 1959) was used for this purpose.

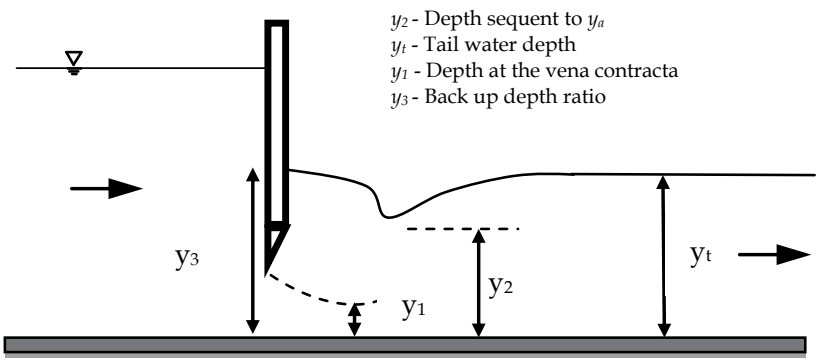

Figure 4 - Submerged hydraulic jump

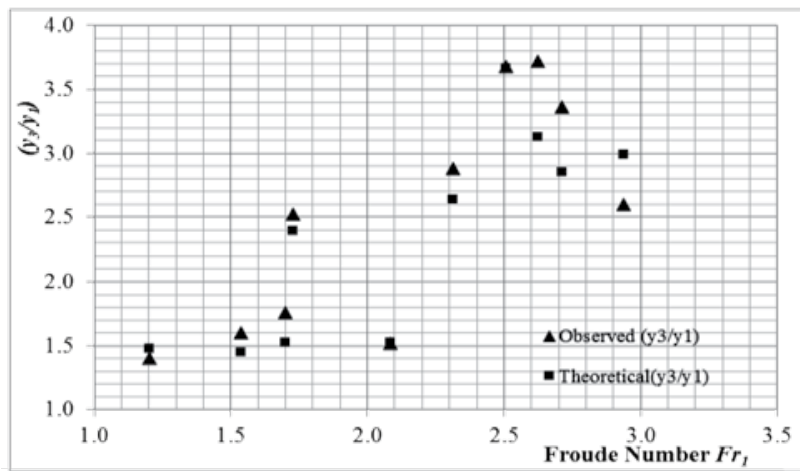

Figure 5 - $\left(y_{3} / y_{1}\right)$ versus upstream Froude number

Figure 5 shows the comparison of backup depth ratio $\left(y_{3} / y_{1}\right)$ versus upstream Froude number using experimental data and theoretical formulation suggested by Rao (1963). The data points are highly scattered on this plot for both the experimental results and the theoretical formulation used to compute backup depth ratio and upstream Froude number. It could be mainly due to the fact that the channel bed roughness has not been correctly represented in these relationships. Only feature that could be noticed here is that the backup depth ratio increases with upstream Froude number. Therefore, this has clearly justified that a new formulation needs to be developed in order to relate the hydraulic parameters associated with submerged hydraulic jumps on rough beds.

\subsection{Dimensional Analysis}

The parameters that affect the characteristics of the hydraulic jumps can be identified as;

$$
\left(y_{1}, V, g, v, t, D, S\right)
$$

where, $y_{1}=$ Depth at Vena-contracta, $t=$ Height of roughness elements, $v=$ Kinematic viscosity of the fluid, $V=$ Velocity at the upstream side of the hydraulic jump, $S=$ Submergence factor and $D=$ Spacing between roughness elements. Using Buckingham's pi theorem, the following relationship can be derived with non- dimensional terms relating the parameters considered above.

$\frac{y_{1}}{\mathrm{y}_{2}}=f\left(F r=\frac{v_{1}}{g \times y_{1}}, \operatorname{Re}=\frac{v_{1} \times y_{1}}{v}, \frac{t}{y_{1}}, \frac{D}{y_{1}}, \frac{S}{y_{1}}\right)$

For turbulent flows, viscous effect can be neglected and hence, the Reynolds number can be omitted from the above equation and it is rewritten as,

$\frac{y_{1}}{\mathrm{y}_{2}}=f\left(F r, \frac{t}{y_{1}}, \frac{D}{y_{1}}, \frac{S}{y_{1}}\right)$

Previous research studies reported by Ead and Rajaratnam (2002), Habibzadeh et.al, (2012) and Habibzadeh et.al, (2011) in the same field, have also taken a somewhat similar approach to analysis the experimental data obtained for submerged hydraulic jumps on rough channel beds. However in all those studies, only one term $\left(t / y_{1}\right)$ which represents the effect of roughness height, had been considered in deriving formulations for characteristics of submerged hydraulic jump on rough beds. Any other term to represent the spacing of roughness element or roughness density has not been considered in any of their studies which appear to be one of the major shortcomings of the previous studies. Perhaps this could have been one of the reasons for poor performance of these available formulations when applying the experimental data that are presented in Sec. 3.1.

In order to overcome the above shortcoming, the present study extends the analysis of submerged hydraulic jumps on rough beds to incorporate the effect of roughness density $(d)$ into the analysis in addition to the roughness heights.

\subsection{Development of a relationship between backup depth ratios and submergence factor}

The behaviour of submerged hydraulic jumps mainly depends on the hydraulic parameters such as backup depth ratio, submergence factor and upstream Froude number. Relationship between these parameters can be identified by plotting various graphs.

Rao (1963) has derived Eq. (3.3) for backup depth ratio of submerged hydraulic jumps in rectangular smooth channels using principles of momentum and continuity equations. It can be noted that the backup depth ratio is clearly 
expressed in terms of sequent depth ratio, submergence factor and upstream Froude number.

$$
\frac{y_{3}}{y_{1}}=\sqrt{(1+S)^{2} \phi^{2}-2 F_{1}^{2}+\frac{2 F_{1}^{2}}{(1+S) \phi}}
$$

where,

$$
S=\frac{y_{t}-y_{2}}{y_{2}} ; \phi=\frac{y_{2}}{y_{1}}=\frac{1}{2}\left(\sqrt{1+8 F_{1}^{2}}-1\right)
$$

Therefore, when it comes to the present study, if an equation for backup depth ratio is to be developed for submerged hydraulic jumps on rough horizontal channel beds, the already derived equation for sequent depth ratio can be used with appropriate changes. Furthermore, in order to make a correction for submergence factor, dimensionless element thickness $\left(t / y_{1}\right)^{n 1}$ and roughness density $(d)^{\mathrm{n} 2}$ were taken into account by examining the equations developed by Habibzadeh et.al., (2012) and also considering the results from dimensional analysis. The equation derived for free hydraulic jump on rough beds is given as;

$$
\phi=\frac{y_{2}}{y_{1}}=\frac{1.0453\left(1-\left(0.1 \frac{t}{y_{1}}\right)\right) F r_{1}+0.1586 \ldots}{(1-|0.15-d|)}
$$

where,

$$
d=\frac{\text { Element width }(t)}{\text { Spacing }(D)}
$$

With that, the analysis of data would have to be considered for two separate flow regimes as follows (Habibzadeh, et.al., 2012);
a. Deflected surface jet (DSJ)
b. Reattaching wall jet (RWJ)

According to the previous studies by Habibzadeh, et.al., (2012), the flow has been categorized as the deflected surface jet for lower range of submergence factor. Under this regime, the energy dissipation of submerged hydraulic jumps was also found to be considerably higher than that of reattaching wall jet regime. But, as the energy dissipation of deflected surface jet is high, there would be an extra reduction of $y_{3}$ and as a result, $\left(y_{3} / y_{1}\right)$ observed here would not match with the theoretical $\left(y_{3} / y_{1}\right)$ very much. Hence, the data analysis should fall under the regime of reattaching wall jet to get an accurate relationship. The data were considered according to the range of submergence factor as well as energy dissipation. Figure (6) clearly illustrating the submerged jump energy loss for those two flow regimes.

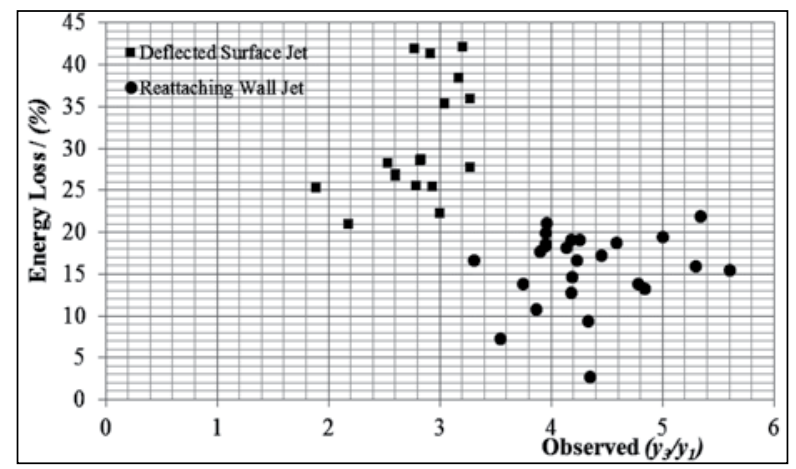

Figure 6 - Percentage of energy loss versus Observed $\left(y_{3} / y_{1}\right)$

From Figure (6) range of $\left(y_{3} / y_{1}\right)$ for reattaching wall jet flow regime can be identified. Under this range submergence factors were calculated.

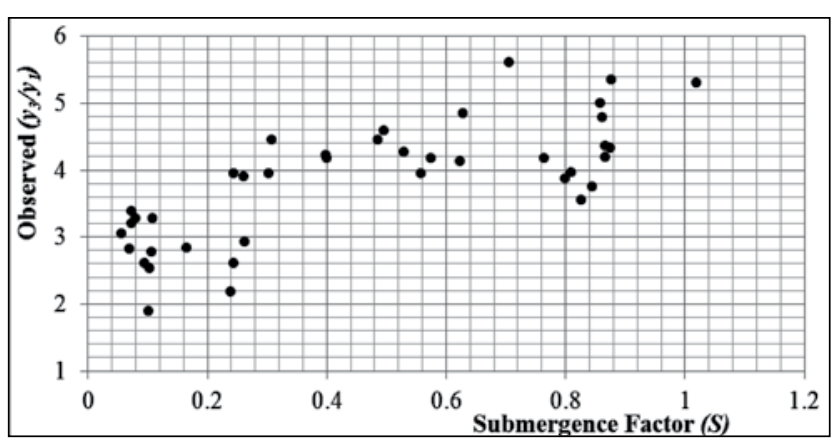

Figure 7 - Observed $\left(y_{3} / y_{1}\right)$ versus Submergence factor

As the data presented in Figure (7) is highly scattered, submergence factor appears to influence the backup depth ratio. In order to find a better correlation between backup depth ratio and submergence factor, additional

$$
\frac{y_{3}}{y_{1}}=\sqrt{\left(1+\left(\frac{t}{y_{1}}\right)^{n_{1}} \times(d)^{n_{2}} s\right)^{2} \phi^{2}-2 F_{1}^{2}+\frac{2 F_{1}^{2}}{\left(1+\left(\frac{t}{y_{1}}\right)^{n_{1}} \times(d)^{n_{2}} s\right) \phi}}
$$

correction for submergence factor is needed. For that roughness density terms were used as mentioned in the section 3.3.

By trial and error, the values of the coefficients $n_{1}$ and $n_{2}$ were found to be 0.33 and 0.44 , respectively to give better correlation between $\left(y_{3} / y_{1}\right)$ and $S$ as given in Eq.(3.6).

$$
\frac{y_{3}}{y_{1}}=\sqrt{\left(1+\left(\frac{t}{y_{1}}\right)^{0.33} \times(d)^{0.44} s\right)^{2} \phi^{2}-2 F_{1}^{2}+\frac{2 F_{1}^{2}}{\left(1+\left(\frac{t}{y_{1}}\right)^{0.33} \times(d)^{0.44} s\right) \phi}}
$$


The validation of Eq. (3.6) was carried out by replacing the term $(\phi)$ obtained from previous studies. Experimental data from the present study were used in all the equations derived by previous researchers and the relevant term was substituted in the Eq. (3.6) for each case. From that, the graph was plotted between the theoretical and observed $\left(y_{3} / y_{1}\right)$ as shown in Figure (3.5).

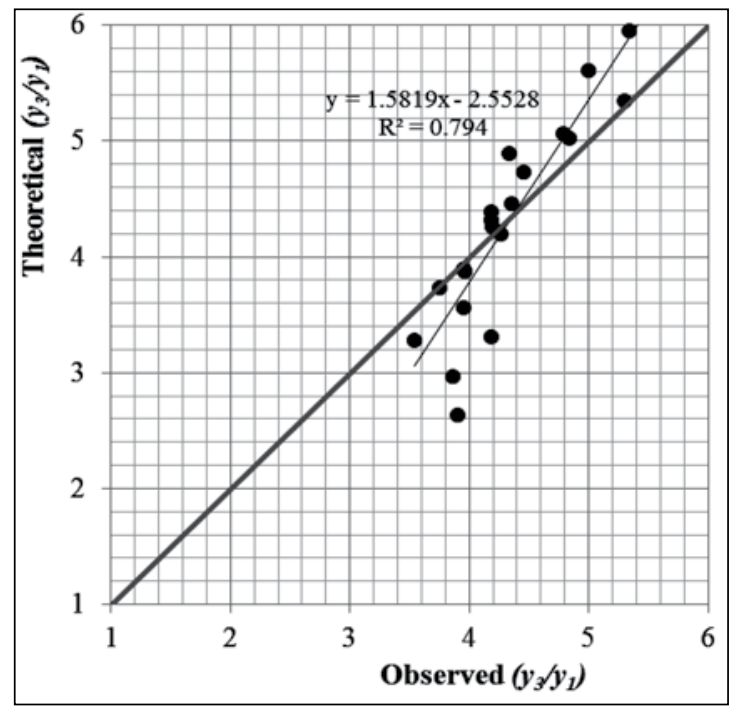

Figure 8 - Theoretical $\left(y_{3} / y_{1}\right)$ versus Observed $\left(y_{3} / y_{1}\right)$ for Reattaching wall jet flow regime

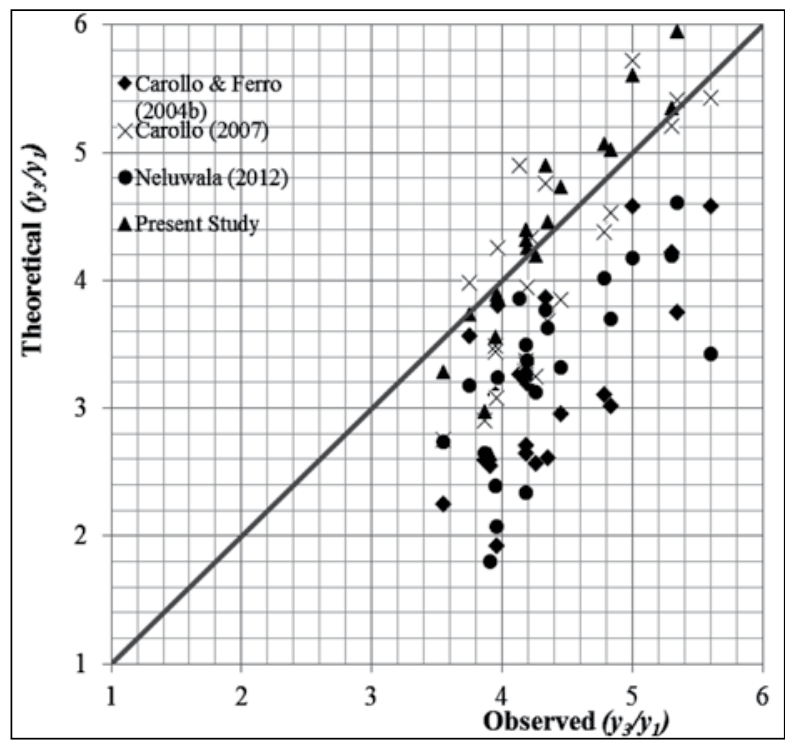

Figure 9 - Theoretical $\left(y_{3} / y_{1}\right)$ versus Observed $\left(y_{3} / y_{1}\right)$ for Reattaching wall jet

From the Figure (9), it can be verified that the derived equation predicts more accurate values.

\subsection{Development of a relationship between} backup depth ratio and tail water depth

For further analysis of data, an equation for $\left(y_{3} / y_{2}\right)$ in terms of $\left(y_{t} / y_{2}\right)$ was obtained from the research study by Habibzadeh, et.al. (2011). Therefore, to compare the observed $\left(y_{t} / y_{2}\right)$ of the present study with this above finalized Eq.(3.6), a graph was plotted after rearranging the terms for $\left(y_{3} / y_{2}\right)$ as shown in Eq. (3.7) by multiplying by $\left(y_{1} / y_{2}\right)$ on both sides of the Eq. (3.6).

$$
\frac{y_{3}}{y_{2}}=\frac{y_{1}}{y_{2}} \sqrt{\left(1+\left(\frac{t}{y_{1}}\right)^{0.33} \times(d)^{0.44} s\right)^{2} \phi^{2}-2 F_{1}^{2}+\frac{2 F_{1}^{2}}{\left(1+\left(\frac{t}{y_{1}}\right)^{0.33} \times(d)^{0.44} s\right) \phi}}
$$

To simplify the Eq. (3.7), $\left(y_{1} / y_{2}\right)$ can be replaced by $1 / \phi$ and the equation can be rewritten as follows;

$\frac{y_{3}}{y_{2}}=\frac{1}{\phi} \sqrt{\left(1+\left(\frac{t}{y_{1}}\right)^{0.33} \times(d)^{0.44} s\right)^{2} \phi^{2}-2 F_{1}^{2}+\frac{2 F_{1}^{2}}{\left(1+\left(\frac{t}{y_{1}}\right)^{0.33} \times(d)^{0.44} s\right) \phi}}$

Figure (10) shows the comparison between the theoretical $\left(y_{3} / y_{2}\right)$ and observed $\left(y_{3} / y_{2}\right)$ using Eq.(3.8). It can be seen that the Eq. (3.8) predicts accurate values with a regression coefficient of above $80 \%$.

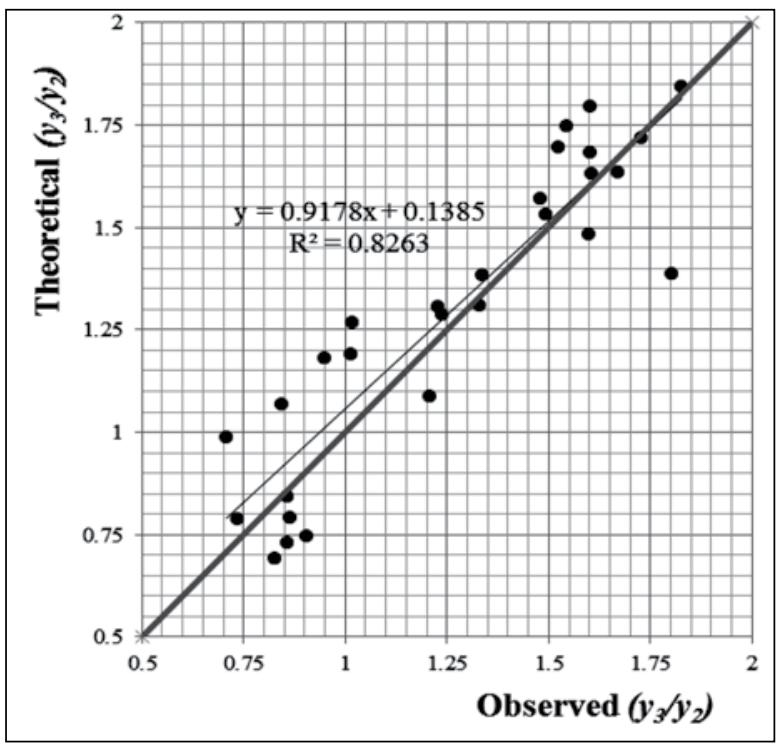

Figure 10 - Theoretical $\left(y_{3} / y_{2}\right)$ versus Observed $\left(y_{3} / y_{2}\right)$ 


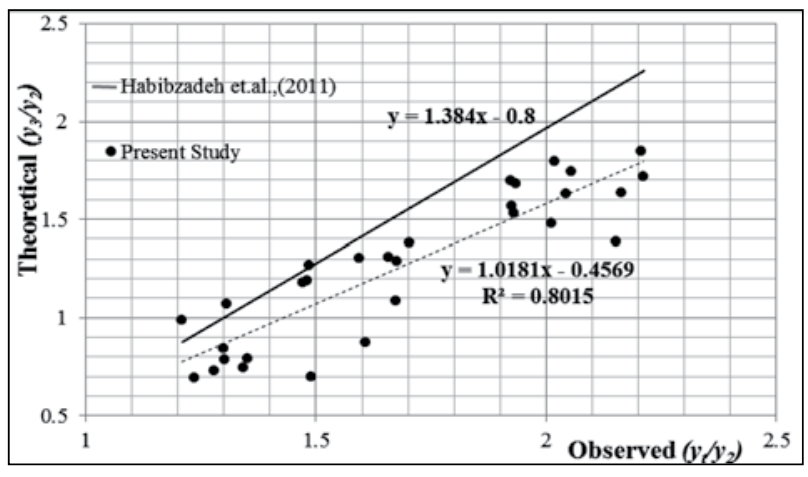

Figure 11- Theoretical $\left(y_{3} / y_{2}\right)$ versus Observed $\left(y_{t} y_{2}\right)$ for the experimental data collected from the present study

When comparing the theoretical $\left(y_{3} / y_{2}\right)$ versus observed $\left(y_{t} / y_{2}\right)$ of the research study by Habibzadeh et. al., (2011) with that of present study as shown in Figure (11), the equation suggested from the present study is acceptable as the obtained a higher regression coefficient.

\subsection{Conclusion and Recommendations}

When free jumps are considered, the variation between Sequent depth ratio and Froude number is found to be nearly linear. Although an aluminium surface was used as the smooth bed condition, the sequent depth ratio was appeared to have decreased by $11 \%$ due to minor surface roughness. The existing theoretical equation for sequent depth ratio has been modified taking this reduction into account. For artificially roughened bed conditions, it was found that the characteristics of submerged hydraulic jumps were a function of submergence factor, in addition to Froude number, roughness height and roughness density which influenced the jump characteristics of free jumps. It was also found that maximum effect of roughness elements occurs at a roughness density of 0.15 .

The energy dissipation is considerably high in the DSJ flow regime condition. Therefore, it is important to ensure that the flow regime is in the DSJ regimes when designing an energy dissipation structure. It can be limited by the critical submergence factor range. To continue with the design procedure, the equation derived above will be very useful to find the water depths.

The conclusion made by Habibzadeh, et. al., (2012) which points out that the DSJ regime, which occurs at smaller submergence factors, is more efficient in terms of energy dissipation than the RWJ regime, because the energy dissipation efficiency decreases with the submergence factor as verified in this study. The study was carried out for flow rate ranging from 4 to $12 \mathrm{l} / \mathrm{s}$ and Froude numbers ranging from 1 to 5 . The results can be further extended if more experiments are carried out to cover higher ranges of Froude numbers. The methodology of the study can also be improved by changing the roughness elements across the flume. Usage of more accurate measuring instruments such as current meters to measure velocities and digital depth gauges would give more accurate results for energy dissipation.

During the present study, only the artificial roughness elements were used to prepare the rough beds, and this can be expanded by using uniform sizes of sand or gravel particles to roughen the channel bed, as it would represent the field conditions much better. Experiments can also be done by changing the bed slopes to include the effect of channel flow on submerged hydraulic jumps. Although the experimental results obtained during this study are reasonably good, it can be further improved by considering above mentioned recommendations.

\section{References}

1. Chow, V. T. (1959), Open Channel Hydraulics. United States: McGraw-Hill.

2. Carollo, F. G., Ferro, V., \& Pampalone, V. (2007), "Hydraulic Jumps on Rough Beds", Journal of Hydraulic Engineering, ASCE, Vol. 133, No. 9, pp.989-999.

3. Dey, S. and Sarkar, A. (2006), Response of Velocity and Turbulence in Submerged Wall Jets to Abrupt Changes from Smooth to Rough Beds and its Application to Scour Downstream of an Apron. Journal of Fluid Mechanics, ASCE, Vol.556, pp.387-419.

4. Dey, S. and Sarkar, A. (2008), Characteristics of Turbulent Flow in Submerged Jumps on Rough Beds. Journal of Engineering Mechanics, ASCE, Vol.134, No-1, pp.49-59.

5. Ead, S. and Rajaratnam, N. (2002), Hydraulic Jumps on Corrugated Beds. Journal of Hydraulic Engineering, ASCE, Vol. 128(7), pp.656-663.

6. French, R. H. (1986). Open Channel Hydraulics. Singapore: McGraw-Hill.

7. Habibzadeh, A., Wu, S., Ade, F., Rajaratnam, N., and Loewen, M. R. (2012), Performance of Baffle Blocks in Submerged Hydraulic Jumps. 
Journal of Hydraulic Engineering, ASCE, Vol. 138(10), pp.902-908.

8. Habibzadeh, A., Loewen, M., and Rajaratnam, N. (2011), Exploratory Study of Submerged Hydraulic Jumps with Blocks. Journal of Hydraulic Engineering, ASCE, Vol.137, No-6, pp.706-710.

9. Hughes, W. C., and Flack, J. E. (1984), Hydraulic Jump Properties over a Rough Bed. Journal of Fluid Mechanics, Science Direct, Vol.110, No-12, pp.1755-1771.

10. Long, D., Steffler, P. M., and Rajaratnam, N. (1990), LDA Study of Flow Structure in Submerged Hydraulic Jump. Journal of Hydraulic Research, Vol.28, No-4, pp.437-460.

11. Neluwala, N. G. P. B., Karunanayake, K. T. S., Sandaruwan, K. B. G. M. and Pathirana, K. P. P. (2012), Characteristics of Hydraulics Jumps over Rough Horizontal Beds. Civil Engineering Research Exchange Symposium, University of Peradeniya.
12. Pagliara, S., Das, R., and Palermo, M. (2008), Energy Dissipation on Submerged Block Ramps. Journal of Irrigation and Drainage Engineering, ASCE, Vol. 134, No.4, pp.527-532.

13. Rajaratnam, N. (1967), Hydraulic jumps. Advances in Hydroscience, Academic Press, Vol.4, pp.197-280.

14. Stefano, P., Ilaria, L. and Michele, P. (2008), Hydraulic Jump on Rough Bed of Stream Rehabilitation Structures. Journal of Hydroenvironment Research, Science Direct, Vol.2, No-1, pp.29-38.

15. Subhasish, D. and Bernhard, W. (2003), Hydraulics of Submerged Jet Subject to Change in Cohesive bed Geometry. Journal of Hydraulic Engineering, Vol.129, pp.44 - 53.

16. Wu, S., and Rajaratnam, N. (1995), Effect of Baffles on Submerged Flows. Journal of Hydraulic Engineering, ASCE, Vol.121, No-9, pp.644-652. 
